\title{
Comparison of Clipless and Clipped Laparoscopic Cholecystectomy at Nishtar Hospital Multan, Pakistan
}

\author{
Abdul Manan ${ }^{1}$, Irfan Ahmad ${ }^{1}$, Asher Ahmad ${ }^{1}$, Tariq Jamil' ${ }^{1}$, Muhammad Usman², Muhammad Afzal Sajid ${ }^{2}$ \\ ${ }^{1}$ Associate Professor, Department of Surgery, Nishtar Medical University, Multan, Pakistan \\ ${ }^{2}$ Assistant Professor, Department of Surgery, Nishtar Medical University, Multan, Pakistan
}

\begin{abstract}
Background: Laparoscopic cholecystectomy has become the procedure of choice in the management of gall stone diseases which is commonly performed using titanium clips. Harmonic scalpel is an option for the clipless surgery. The objective of the study was to compare the efficacy of clipless cholecystectomy using harmonic scalpel and clipped conventional laparoscopic cholecystectomy.

Material and Methods: This randomized controlled trial was conducted at Nishtar Hospital Multan, Pakistan from October 1st 2019 to March 31st 2020. Total 188 patients of gallstone related cholecystitis were enrolled in the study. Patients were divided by simple randomization into two equal groups for clipless and the conventional clipped laparoscopic cholecystectomy, respectively. Age, gender, duration of cholecystitis, duration of procedure, hospital stay, usefulness in difficult procedures and biliary leakage were recorded for all the patients. Data was compared between the two groups by applying Student t-test on quantitative variables and Chi square test on the qualitative variables.

Results: Mean operation time was more for clipped (28.35 \pm 7.92 minutes) as compared to clipless cholecystectomy (21.15 \pm 4.47 minutes) $(P<.001)$. Mean hospital stay was $2.37 \pm 0.60$ days in clipped surgery group and $1.71 \pm 0.74$ days in clipless surgery group $(P<.001)$. Biliary leakage was reported in $2(2.1 \%)$ patients of the clipped group and $1(1.1 \%)$ patient of the unclipped group $(P=.561)$. Clipless procedure was found to be more useful in difficult cases $(n=8 ; 8.5 \%)$ as compared to the clipped cholecystectomy $(P=.004)$.

Conclusions: The results in the current study show that clipless surgery is a better option as compared to the clipped conventional laparoscopic cholecystectomy, as it is associated with a shorter operating time and hospital stay along with better usefulness in difficult cases.

Key words: Biliary leakage, Cholecystitis, Clipped laparoscopic cholecystectomy, Clipless laparoscopic cholecystectomy
\end{abstract}

\begin{tabular}{|c|c|c|}
\hline Authors' Contribution: & Correspondence: & Article info: \\
\hline $\begin{array}{l}{ }^{1} \text { Conception; Literature research; } \\
\text { manuscript design and drafting; }{ }^{2-6} \text { Critical } \\
\text { analysis and manuscript review; Data } \\
\text { analysis; Manuscript Editing. }\end{array}$ & $\begin{array}{l}\text { Abdul Manan } \\
\text { Email: drmanan2001@yahoo.com }\end{array}$ & $\begin{array}{l}\text { Received: May 10, } 2020 \\
\text { Accepted: December 28, }\end{array}$ \\
\hline
\end{tabular}

Islamabad Med Dental Coll. 2020; 9(4): 275-279. Doi: 10.35787/jimdc.v9i4.548

\section{Introduction}

Diseases related to gall stones have a diverse clinical presentation. Such patients present in the surgical department with a wide spectrum of symptoms, ranging from mild biliary colic, requiring conservative management to gall stones pancreatitis, which is a life-threatening condition 
and needs urgent surgery. ${ }^{1}$ In recent days, laparoscopic cholecystectomy has become the procedure of choice in the management of gall stone diseases. ${ }^{1}$

Laparoscopic cholecystectomy is a simple and less invasive surgical procedure as compared to open surgery. Usually, titanium clips are used in order to secure cystic duct and cystic artery. There are many drawbacks associated with this technique, as it needs more dissection to apply multiple clips, further it is also a time-consuming procedure. More laparoscopic manipulation can cause bleeding as well as damage to adjacent structures. This incidence has been reported to be $3 \%$ following clipped laparoscopic cholecystectomy as compared to $0.5 \%$ following open cholecystectomy. ${ }^{2}$ Additionally, more sophisticated procedures including drainage and magnetic resonance retrograde cholangiopancreatography (MRCP) are required for the management of biliary leakage. All these prolong the hospital stay of the patient, thus increasing the financial burden on the patient, his family and the health facility and most of all increase the morbidity and mortality. ${ }^{3}$

Harmonic scalpel is an option for the clipless surgery and has been considered as a better choice for securing the cystic artery and cystic duct in order to prevent the risk of biliary leakage following clipped laparoscopic cholecystectomy. ${ }^{4,5}$ Multiple studies have reported that the incidence of biliary leakage was more in clipped as compared to clipless surgeries, respectively. ${ }^{6,7}$ Similar frequency of biliary leakage was reported in another study which was conducted in Rawalpindi, Pakistan. ${ }^{8}$ Others have also observed that the clipped procedures resulted in higher incidence of biliary leakage. ${ }^{3,9}$

The purpose of this study was to compare the efficacy of clipped and clipless cholecystectomy in the management of gallstone-related cholecystitis. Local data regarding newer techniques is very limited. Therefore, current study was planned to identify techniques used at our local health facilities, which can help the practitioners to implement evidence-based safer surgical techniques.

\section{Material and Methods}

This randomized controlled trial was conducted in the Department of General Surgery at Nishtar Hospital Multan, Pakistan from October $1^{\text {st }} 2019$ to March $31^{\text {st }} 2020$. Ethical approval was obtained from the Institutional Ethical Review Board, Nishtar Medical University, Multan. Informed written consent was taken from all the patients. A sample of 188 patients of gallstone-related cholecystitis was calculated using incidence of clipless laparoscopic cholecystectomy (13.8\%) and conventional clipped cholecystectomy (30.7\%), ${ }^{10}$ with $80 \%$ power of study and $20 \%$ risk of type II error (beta $=0.2$ ). ${ }^{10} \mathrm{~A}$ nonprobability consecutive sampling technique was used. Patients of both genders were randomly included in the study. Patients having complicated diabetes mellitus, ischemic heart disease, deranged clotting profile, gallbladder malignancy and acute cholecystitis for more than 7 days were excluded from the study. Patients were fully evaluated by the operating surgeon to meet the eligibility criteria of laparoscopic cholecystectomy before the surgery.

Patients were divided into two equal groups by simple randomization. One group was designated for clipless laparoscopic cholecystectomy and the other for conventional clipped laparoscopic cholecystectomy. Harmonic scalpel using ultrasonic shear (Olympus Keymed SonoSurg version G2 220$240 \mathrm{~V} 3 \mathrm{~A} .50 / 60 \mathrm{~Hz}$.) was applied for removal of gall bladder in the clipless surgery. Conventional clipping instruments were used for removing gall bladder in clipped surgery group. Standard procedure and protocols were used by the consultant surgeon for the procedure. Drain was kept in place at the end of surgical procedure. Patients were kept under observation for 24 hours postoperatively and were monitored for the oozing of fluid or blood in the 
drain. Patients were discharged from the hospital with the advice to follow up after one week. Consultant radiologists performed magnetic resonance cholangiopancreatography (MRCP) in suspected cases of the biliary leakage.

Age, gender, duration of cholecystitis, operation time, hospital stay, usefulness in difficult cases and biliary leakage were recorded for all the patients. Data was entered in SPSS version 23 and analyzed. Quantitative variables such as age, procedure time and hospital stay were presented as mean and standard deviation. Qualitative variables such as gender, duration of cholecystitis, usefulness in difficult procedures and incidence of biliary leakage were presented as number and percentage. Data was compared between the two groups by applying student t-test on quantitative variables and chi square test on the qualitative variables. Incidence of biliary leakage was compared between the two groups by chi square test and $P$-value less than 05 was considered as statistically significant.

\section{Results}

Mean age of the patients was $44.59 \pm 7.52$ years in the clipped group and $45.33 \pm 11.45$ years in the clipless group $(P=.604)$. Gender distribution for both groups is shown in Table I.

Mean operation time was more for clipped (28.35 \pm 7.92 minutes) as compared to clipless cholecystectomy $(21.15 \pm 4.47$ minutes $)(P<.001)$. Mean hospital stay was $2.37 \pm 0.60$ days in clipped surgery group and $1.71 \pm 0.74$ days in clipless surgery group $(P<.001)$. Biliary leakage was reported in 2 (2.1\%) patients of the clipped group and 1 (1.1\%) patient of the unclipped group $(P=.561)$. Clipless procedure was found to be more useful in difficult cases $(n=8 ; 8.5 \%)$ as compared to the clipped procedures $(P=.004)$ (Table II).

There were 8 (8.5\%) difficult cases in the clipless group which were successfully dealt with laparoscopically. There were 10 (10.6\%) difficult cases including 2 (2.1\%) cases of biliary leakage in the clipped group which were converted into open cholecystectomy considering the safety of the patients.

\begin{tabular}{|l|c|c|c|}
\hline \multicolumn{3}{|c|}{ Table I: Demographic data of the two groups } \\
\hline Variable & Clipped (n=94) & Clipless (n=94) & $\begin{array}{c}\text { P- } \\
\text { value* }\end{array}$ \\
\hline $\begin{array}{l}\text { Mean Age } \\
\text { (years) }\end{array}$ & $44.59 \pm 7.52$ & $45.33 \pm 11.45$ & .604 \\
\cline { 1 - 2 } $\begin{array}{l}\text { Male } \\
\text { (\%) }\end{array}$ & $35(37.2 \%)$ & $37(39.4 \%)$ & \multirow{2}{*}{.764} \\
\cline { 1 - 3 } $\begin{array}{l}\text { Female } \\
\text { n (\%) }\end{array}$ & $59(62.8 \%)$ & $57(60.6 \%)$ & \\
\cline { 1 - 3 }
\end{tabular}

${ }^{*} P$-value $<.05$ was taken as statistically significant

\begin{tabular}{|l|c|c|c|}
\hline \multicolumn{4}{|c|}{$\begin{array}{c}\text { Table II: Outcome data regarding operating time, } \\
\text { hospital stay and complications }\end{array}$} \\
\hline Outcome & Clipped & Clipless & $\begin{array}{c}\boldsymbol{P} \text { - } \\
\text { value }\end{array}$ \\
\hline $\begin{array}{l}\text { Operation } \\
\text { time (minutes) }\end{array}$ & $28.35 \pm 7.92$ & $21.15 \pm 4.47$ & $<.001$ \\
\hline $\begin{array}{l}\text { Hospital stay } \\
\text { (days) }\end{array}$ & $2.37 \pm 0.60$ & $1.71 \pm 0.74$ & $<.001$ \\
\hline Biliary leakage & $2(2.1 \%)$ & $1(1.1 \%)$ & .561 \\
\hline $\begin{array}{l}\text { Usefulness in } \\
\text { difficult } \\
\text { procedures }\end{array}$ & $0(0.0 \%)$ & $8(8.5 \%)$ & .004 \\
\hline
\end{tabular}

${ }^{*} P$-value $<.05$ was taken as statistically significant

\section{Discussion}

In contrast to open cholecystectomy, laparoscopic cholecystectomy is an economical, simple, and safe choice. ${ }^{11}$ The major procedures included in the cholecystectomy are removing the gall bladder, and securing the cystic artery and cystic duct. These structures can be secured either by extracorporeal or intracorporeal ligation. ${ }^{12}$ The common complication of ligation is the biliary leakage, and this demands a safer procedure such as clipless surgery. This type of surgery uses harmonic scalpel and LigaSure, which are the latest advancement in the laparoscopic surgery. ${ }^{13,14}$ 
In the current study, biliary leakage was reported in $2(2.1 \%)$ patients of the clipped group and $1(1.1 \%)$ patient of the clipless group. The procedure time and hospital stay were significantly shorter in the clipless surgery patients and it was also found to be more useful in dealing with difficult cases.

Bessa et al. ${ }^{6}$ reported in their study that clipless surgery is safe with lesser complications related to biliary leakage, following gall bladder perforation. Gall bladder perforation during clipped laparoscopic cholecystectomy was $30 \%$ as compared to clipless surgery in which incidence of GB perforation was $10 \%$. However, no cases of postoperative biliary leakage were observed in both the groups. The median operation time was also significantly shorter in the clipless surgery group.

Another study reported significantly less incidence of gall bladder perforation in the clipless surgery, however the incidence of biliary leakage was not significantly different in the clipped (3.3\%) and clipless surgery group (1.7\%) $(P=.45) .{ }^{9}$ The operation time was also shorter in the clipless surgery group. The conversion rate of laparoscopic procedure to open procedure was higher in the clipped group but the difference was not significant $(P=.65) .{ }^{9}$ A study conducted in Rawalpindi found similar results (3.6\% vs. $3.4 \%)$ in both the groups $(P=.972)$ but the operation time was shorter in the harmonic scalpel group. ${ }^{8}$ Akhtar et al. observed biliary leakage in 9 patients of the clipless group and 20 patients of the clipped group $(P=.020){ }^{10}$

Saha et al. conducted a study in Bangladesh and reported that the clipless cholecystectomy is an effective and safe method for removing gall bladder as it is associated with less incidence of gall bladder perforation and biliary leakage. ${ }^{15}$ Another study conducted by Gelmini et al. showed that mean operative time was significantly shorter in the group operated upon by the harmonic scalpel. ${ }^{16}$ The biggest hurdle in the way of using harmonic scalpel is the requirement of expertise and expensive instruments, which are difficult to procure in a developing country like Pakistan. Harmonic scalpels should at least be made available in the tertiary care health facility. This can facilitate clipless surgery reducing the procedure time of cholecystectomy along with postoperative morbidity and thus reducing mortality. This will also reduce the rate of conversion of laparoscopic cholecystectomy to open cholecystectomy.

Amarin suggested that the use of harmonic scalpel for conducting clipless laparoscopic cholecystectomy is an efficient, safe and practical approach and the role of this technique can easily be expanded including complete hemobiliary stasis. ${ }^{17}$ Another study conducted in Lahore observed no statistically significant difference between the groups in terms of postoperative complications, gall bladder perforation and biliary leakage. ${ }^{18}$ However, they observed that the duration of the surgery was significantly shorter in the clipless group in which surgery was performed using harmonic scalpel. ${ }^{18}$.

\section{Conclusion}

Clipless surgery is a better option as compared to the clipped conventional cholecystectomy, as it is associated with a shorter operating time and hospital stay along with better usefulness in difficult cases. However, there was no difference in terms of biliary leakage. Clipless surgery can be applied easily in patients as it is associated with decreased morbidity and hence lower mortality.

\section{References}

1. Demehri FR, Alam HB. Evidence-based management of common gallstone-related emergencies. J Intens Care Med. 2016; 31(1): 3-13. Doi: $10.1177 / 0885066614554192$.

2. Kassem MI, Hassouna EM. Short-term outcome of total clipless laparoscopic cholecystectomy for complicated gallbladder stones in cirrhotic patients. ANZ J Surg. 2018; 88(3): E152-56. Doi: 10.1111/ans.13855 
3. Hassan G, Gulzar S, Iqbal T, Haque MI. Clipless laparoscopic cholecystectomy: 3 Port access. Professional Med J. 2020; 27(06): 1124-27. DOI: 10.29309/TPMJ/2020.27.06.3549

4. Weber A, Feussner $H$, Winkelmann F, Siewert JR, Schmid RM, Prinz C. Long-term outcome of endoscopic therapy in patients with bile duct injury after cholecystectomy. J Gastroenterol Hepatol. 2009; 24(5) :762-69. Doi: 10.1111/j.14401746.2008.05713.x.

5. Di Lascia A, Tartaglia N, Fersini A, Petruzzelli F, Ambrosi A. Endoscopy for treating minor postcholecystectomy biliary fistula. Ann. Ital. Chir. 2018; 89(3): 270-77. PMID: 30588923

6. Sanawan E, Qureshi AU, Qureshi SS, Cheema KM, Cheema MA. Effectiveness of ultrasound shear for clipless laparoscopic cholecystectomy versus conventional unipolar electrocautery in patients with cholelithiasis. J Coll Physicians Surg Pak. 2017; 27(10): 611-5. PMID: 29056121

7. Wills $E$, Crawford $G$. Clipless versus conventional laparoscopic cholecystectomy. J Laparoendosc Adv Surg Tech. 2013; 23(3): 237-9. Doi: 10.1089/lap.2012.0387

8. Khan JS, Qureshi U, Fatima Z, Hassan H, Khan MM, Iqbal M. Clipless laparoscopic cholecystectomy by Ultrasonic. Ann Pak Inst Med Sci. 2012; 8(4): 229-31.

9. El Nakeeb A, Askar W, El Lithy R, Farid M. Clipless laparoscopic cholecystectomy using the Harmonic scalpel for cirrhotic patients: a prospective randomized study. Surg Endoscop. 2010; 24(10): 2536-41. doi: 10.1007/s00464-010-0999-9

10. Akhtar HS, Farooq Z, Rathore H, Farooq MU, Ahmad A. Clipped or clipless cholecystectomy; which option to choose to prevent postoperative biliary leakage in patients of cholecystitis. Prof Med J. 2018; 25(6).
11. Singal R, Zaman M, Mittal A, Singal S. The safety and efficacy of clipless versus conventional laparoscopic cholecystectomy-our Experience in an Indian Rural Center. Maedica. 2018; 13(1): 44-50. PMID: 29868139

12. Wang EY. The Tips and Tricks of the Suture in Urologic Laparoscopy. In The Training Courses of Urological Laparoscopy 2012; 113-137.

13. Kandil T, El Nakeeb A, El Hefnawy E. Comparative study between clipless laparoscopic cholecystectomy by harmonic scalpel versus conventional method: a prospective randomized study. J Gastrointestinal Surg. 2010; 14(2): 323-8. Doi: 10.1007/s11605-0091039-8

14. Mahmoud Ms, Hamed Ae, Mekki M. Clippless Laparoscopic Cholecystectomy Using Ultrasonic Dissection. Med J Cairo Uni. 2020; 88: 1157-63. Doi: 10.21608/mjcu.2020.110852

15. Saha PK, Roy RR, Rahman M, Khan EH, Reza SM, Rabbani MG, et al. Clipless Laparoscopic Cholecystectomy: An initial experience of 50 cases in Bangladesh. J Sci Foundation. 2015; 13(1): 11-14. Doi: 10.3329/jsf.v13i1.27828

16. Gelmini R, Franzoni C, Zona S, Andreotti A, Saviano M. Laparoscopic cholecystectomy with Harmonic scalpel. JSLS: J Soc Laparoendoscop Surg. 2010;14(1):14. Doi: 10.4293/108680810X12674612014301

17. Amarin NS. Harmonic scalpel and clipless cholecystectomy. World J Laparosc Surg. 2008; 1(2): 6-8.

18. Baloch SH, Afzal SI, Hamid T. Use of harmonic shear vs titanium clips in laparoscopic cholecystectomy: experience in nawaz sharif social security teaching hospital Lahore. Pak J Med Health Sci. 2015; 9(3): 999-1001. 